\title{
The Psychological Impact and Associated Factors of COVID-19 on the General Public in Hunan, China
}

This article was published in the following Dove Press journal:

Risk Management and Healthcare Policy

\section{Chunhong Shi, (D)' Zhihua Guo, ${ }^{2}$ Chan Luo, ${ }^{3}$ Changbin Lei, (iD) ${ }^{4}$ Pan Li' \\ 'School of Nursing, Xiangnan University, Chenzhou 423000, People's Republic of China; ${ }^{2}$ Nursing Department, Changsha Health Vocational College, Changsha 410100 , People's Republic of China; ${ }^{3}$ Nursing Department, The First Affiliated Hospital of University of South China, Hengyang 42 I00I, People's Republic of China; ${ }^{4} \mathrm{Clinical}$ Medicine Research Center, Affiliated Hospital of Xiangnan University, Chenzhou 423000, People's Republic of China}

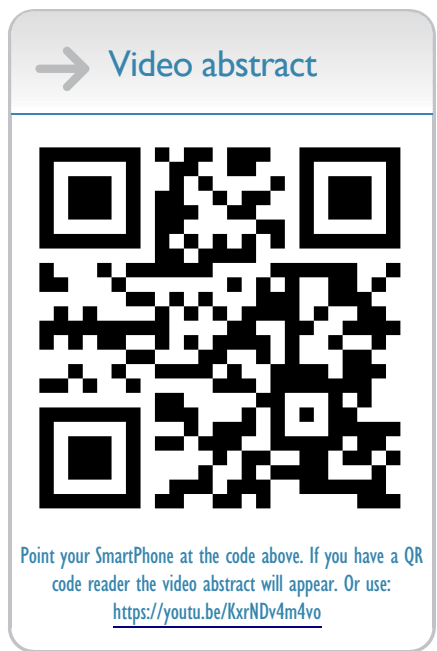

Correspondence: Changbin Lei Clinical Medicine Research Center, Affiliated Hospital of Xiangnan University, No. 25 Renmin West Road, Beihu District, Chenzhou, 423000 Hunan, People's Republic of China

Tel +86 I3762563779

Fax +86-735-2223633

Email leichangbin@xnu.edu.cn

Pan Li

School of Nursing, Xiangnan University, 889 Chenzhou Avenue, Suxian District, Chenzhou, 423000 Hunan, People's Republic of China

Tel +86 17773560292

$\mathrm{Fax}+86-735-2325007$

Email lipan1020@xnu.edu.cn
Purpose: This study aimed to assess the psychological impact of the COVID-19 pandemic among the general public in Hunan Province, China, which could help develop psychological interventions and mental health programs.

Participants and Methods: This online cross-sectional study recruited 571 participants through snowball sampling between February 2 and February 5, 2020. Data were collected through a general information questionnaire, the Public Emergency Psychological State Questionnaire, the Simple Coping Style Questionnaire, and the Public Disease Awareness on COVID-19 Scale.

Results: The total mean score of the public emergency psychological state of the sample was $0.27(0.31)$ points, with only $5.78 \%$ of participants $(n=33)$ developing psychological distress. Avoidant coping style and disease awareness were weakly positively correlated $\left(\mathrm{r}_{\mathrm{s}}=\right.$ $0.257, \mathrm{p}<0.01)$ and weakly negatively correlated $\left(\mathrm{r}_{\mathrm{s}}=-0.124, \mathrm{p}<0.01\right)$ with psychological responses, respectively. There were significant psychological differences among the following variables: occupation, symptoms of fever or fatigue, discernment of the authenticity of COVID-19 information, and level of concern regarding COVID-19 ( $p<0.05)$.

Conclusion: The COVID-19 pandemic appears to have had a minor psychological impact on the general population in Hunan Province. However, psychological health promotion in the general public is still required, especially for employees (such as company employees, migrant workers, and businessmen), individuals with COVID-19-like symptoms, limited discernment competence and unconcerned attitudes.

Implications: The initiatives for improving psychological health among the general public could focus on delivering COVID-19 knowledge and alleviating avoidant coping styles. Our findings could provide important insight for the development of psychological support strategies in China, as well as in other places affected by the epidemic.

Keywords: coping style, coronavirus disease 2019, disease awareness, psychological health, public health emergency

\section{Introduction}

As an international public health emergency, the coronavirus disease 2019 (COVID19) has gained widespread attention from the public. Owing to COVID-19's high infectivity and mortality rate $(3-4 \%),{ }^{1}$ China initiated its first-level public health emergency response on January $25,2020 .^{2}$ The Chinese government and health authorities strived to slow the virus' spread by adopting a series of preventive measures, such as strict quarantining, contact tracing, and social distancing. ${ }^{3}$ In addition to the health-related and socio-economic concerns associated with COVID19 , the psychological impact of the disease has also attracted considerable attention. In March, the World Health Organization ${ }^{4}$ released mental health guidelines to support the psychosocial and mental well-being of the general population. 


\section{Background}

With the virus' exponential diffusion and the related largescale quarantine policies enacted by most governments, a wide range of psychological disorders, including panic, fear, anxiety, depression, and frustration, gradually emerged. To date, various studies have reported the psychological impact of the COVID-19 pandemic on different populations. For example, patients with COVID-19 have been reported to not only experience several physical symptoms but also diverse psychological effects. ${ }^{5}$ Similarly, healthcare providers, especially nurses and physicians caring for COVID-19 patients, experience considerable psychological distress associated with fear of infection. ${ }^{6}$ The general population is simultaneously affected by COVID-19 infection as well as social distancing measures. Qiu et $\mathrm{al}^{7}$ found that $5.14 \%$ of the Chinese public experienced severe mental distress. Another Chinese online study by Wang et $\mathrm{al}^{8}$ showed that $16.5 \%$ of the general population had moderate to severe depressive symptoms and $28.8 \%$ suffered from moderate to severe anxiety symptoms. As the virus spreads globally, studies on the psychological impact of the COVID-19 pandemic have proliferated among different nations. ${ }^{9,10}$ For instance, an Australian nationwide survey found that the mental problems of residents during the pandemic were at least twice as high as those prior to the pandemic. ${ }^{11}$ Italian series of studies have reported that the COVID-19 pandemic was an important stressor comparable to a traumatic event. ${ }^{12-14}$

Stress is a physiological, psychological, and behavioral process that occurs in individuals as a response to environmental stimuli. ${ }^{15}$ Previous studies have demonstrated that stress causes various mental health problems. ${ }^{16,17}$ Although moderate pressure is beneficial to stimulate individual protective behaviors and improve environmental adaptability by developing a warning system, ${ }^{18,19}$ long-term or intense stress causes psychological impairment and physical disease. This phenomenon has been explained through a stress system model, which suggests that adverse life events (stressors) can directly lead to individual stress responses or indirectly affect an individual's physical and mental health through their coping style, social support, personality traits, and awareness. ${ }^{20}$ Figure 1 shows the stress system model.

Coping style refers to individuals' cognitive and behavioral efforts to maintain mental balance in stressful situations. ${ }^{21}$ Previous studies demonstrated that coping style functions as a mediator between stress and psychological health. ${ }^{22}$ Adopting appropriate coping strategies against stressful situations is positively linked to quality of life. ${ }^{23}$ Additionally, the role of coping strategies in medical settings has been well-documented. For example, task-based coping strategies appear to prevent the onset of depressive symptoms ${ }^{24}$ and help reduce the severity of hypertension. ${ }^{25}$ Disease awareness (which refers to the self-evaluation of knowledge about disease transmission, common symptoms, potential treatment, and risk factors associated with the disease) ${ }^{26}$ is critical to control and prevent COVID-19. Further, having knowledge about a specific disease can influence individuals' perception and behavior towards it. ${ }^{27}$ Earlier studies have shown that a higher level of COVID-19 knowledge is beneficial for the public to maintain an optimistic attitude and maintain appropriate preventive measures and care-seeking behaviors. ${ }^{28}$ In addition, research during the SARS outbreak suggests that the public's knowledge was associated with a reduction in

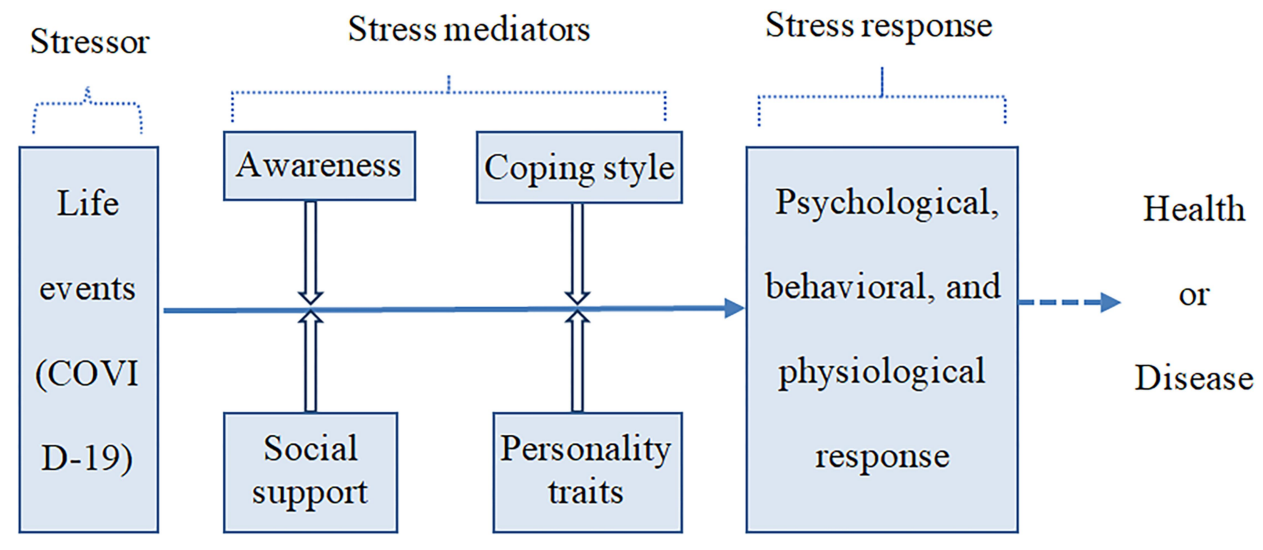

COVID-19: coronavirus disease 2019

Figure I Adaptation of the theoretical framework of the stress system model. 
symptoms of anxiety, fear and panic. ${ }^{29}$ Limited disease knowledge may aggravate psychological distress and emotional responses. ${ }^{30}$ Therefore, coping styles and disease awareness play a significant role in handling the psychological stress associated with the COVID-19 pandemic.

There is already extensive literature regarding mental health and psychosocial distress during the COVID-19 pandemic. However, in terms of survey tools, most studies have used general scales (such as the Symptom Checklist-90 or the Depression, Anxiety, and Stress Scale) rather than scales specifically targeted for public health emergencies. Further, although researchers have conducted nationwide surveys in China, information on specific regions remains limited. Hunan is one of the neighboring provinces with close transport links to Wuhan. Thus, understanding the potential psychological changes associated to the pandemic among the population of Hunan is essential to improve individuals' mental health through targeted interventions.

\section{Aims}

This study aimed to 1) understand the psychological state of the general public in Hunan during the COVID-19 pandemic, and 2) explore which factors influence the public's psychological state and analyze the association of psychological state with coping style and disease awareness.

\section{Materials and Methods Design}

This cross-sectional, descriptive study employed an online questionnaire to survey individuals from Hunan Province, China, regarding their psychological state during the COVID-19 pandemic.

\section{Participants}

All respondents were Chinese citizens from Hunan Province who consented to participate and completed the online questionnaire. Candidates were selected using snowball sampling between February 2 and February 5, 2020 (the early second stage of China's fight against the epidemic). The inclusion criteria were: 1) being from Hunan Province, 2) aged 18-60 years, 3) being able to speak and understand Chinese, and 4) being able to complete the online questionnaire independently. We excluded individuals who were: 1) confirmed COVID-19 patients and 2) frontline medical staff involved in COVID-19 pandemic control. According to Kendall's sample size calculation method, the sample size should be $5-10$ times the number of items in the questionnaire. ${ }^{31}$ Therefore, considering three scales comprising 54 items, a sample size of 270-540 was required for this study. Assuming a $20 \%$ dropout rate, the study needed a sample size of 324-648 participants. Finally, 571 valid questionnaires were obtained to meet the sample size requirement.

\section{Survey Tools}

The questionnaire employed in this study consisted of four parts, including a general information questionnaire, the Public Emergency Psychological State Questionnaire, the Simple Coping Style Questionnaire, and the Public Disease Awareness on COVID-19 Scale.

\section{General Information}

This section registered participants' demographic characteristics (such as age, gender, ethnicity, place of residence, educational level, marital status, employment status, monthly income, and religious beliefs) as well as 10 items related to the COVID-19 pandemic, such as the presence or absence of physical symptoms (such as fever, fatigue, or cough) in the past 14 days.

\section{Public Emergency Psychological State Questionnaire} This questionnaire, developed by Gao et $\mathrm{al}^{32}$, is used to evaluate the emotional response to public emergencies among individuals aged 16 years and above. ${ }^{33}$ It comprises 25 items divided into five dimensions: depression (six items), neurasthenia (five items), fear (six items), compulsion-anxiety (six items), and hypochondria (two items). Each item is scored on a four-point scale ranging from 0 to 3 , according to severity (null, mild, moderate, and severe) and frequency (rarely, sometimes, often, and always). The score for each dimension is equal to the total score divided by the number of items. The higher the score, the more severe the individual's emotional response is in that dimension. According to a previous study, the recommended cutoff score is 1 , with scores of $\geq 1$ indicating psychological distress. ${ }^{34}$ The overall Cronbach's $\alpha$ coefficient of this scale was 0.910 , and its split-half reliability was 0.758 in this study. Cronbach's $\alpha$ coefficients for the depression, neurasthenia, fear, compulsion-anxiety and hypochondria subdimensions were 0.885 , $0.846,0.802,0.791$, and 0.802 , respectively.

\section{Simple Coping Style Questionnaire}

$\mathrm{Xie}^{35}$ developed this scale to assess individuals' coping styles. It contains 20 questions divided into two dimensions: 
active coping style (items 1-12) and avoidant coping style (items 13-20). Each item is scored on a four-point Likert scale ranging from 0 to 3 according to frequency (never, sometimes, often, and always). The score for each dimension is equal to the total score divided by the number of items. The higher the coping style score, the more likely the participant would be to employ that specific coping style. In this study, the Cronbach's $\alpha$ coefficients for the entire tool, the active coping style dimension, and the avoidant coping style dimension were $0.894,0.897$, and 0.792 , respectively.

\section{Public Disease Awareness on COVID-19 Scale}

This scale originated from the SARS Socio-psychological Survey (national version) developed by the Institute of Psychology from the Chinese Academy of Sciences. ${ }^{29}$ For our study, we used the first dimension of this scale, which comprised nine questions on COVID-19 pandemic awareness among the general public and was scored on a fivepoint Likert scale ("unfamiliar" $=1$, "slightly familiar" $=2$, "somewhat familiar" $=3$, "moderately familiar" $=4$, and "extremely familiar" $=5$ points). The scale score is equal to the total score divided by nine. The higher the score, the better the COVID-19 pandemic awareness of the general public. In this study, the tool's overall Cronbach's $\alpha$ coefficient was 0.932 and its split-half reliability was 0.847 .

\section{Data Collection}

This survey was conducted on the Questionnaire Star platform (https://www.wjx.cn; Changsha Ranxing Science and Technology, Shanghai, China) using snowball sampling. The questionnaire link was distributed through QQ or WeChat (the most popular social media applications in China) to the contacts of the researchers, who resided in various cities in Hunan Province. In addition to the first contact point, the link was sent out to others as well. Participants were encouraged to distribute the survey to as many people as possible; we expected to cover all cities in Hunan Province. The participants could complete the questionnaire anonymously on their mobile phones or computers by clicking on the hyperlink. Only one submission was allowed for each IP address, computer, or mobile phone. The researchers could check questionnaire responses at any time on Questionnaire Star. A total of 649 responses were obtained. After removing 78 questionnaires that showed non-Hunan IP addresses, contained incorrect information, or those that exhibited an answering pattern, 571 valid questionnaires were included in this study, which had an efficiency rate of $87.98 \%$. Figure 2 shows the distribution of research samples across various cities of Hunan Province.

\section{Ethical Considerations}

The informed consent form on the first page of the online questionnaire explained the objective, process, and possible risks and benefits of this study to the potential participants. After participants provided their consent to participate in the study, they could proceed to answer the questionnaire anonymously and receive a digital payment or a voucher, the value of which ranged from 5 to 10 Chinese RMB (roughly equivalent to $0.70-1.40$ USD) after completing the survey. They were allowed to withdraw from the study at any time without any explanation. The survey data were kept strictly confidential by encrypting and storing them in one personal computer. This study conformed to the guidelines of the 1995 Declaration of Helsinki (and its revised edition from 2000).

\section{Data Analysis}

An Excel spreadsheet was exported from the Questionnaire Star platform. After being verified by two researchers, the data were imported into SPSS Statistics 25.0 software (IBM Corp., Armonk, NY, USA). The Kolmogorov-Smirnov normality test was performed on continuous data. The normality tests showed that all continuous variables had a non-normal distribution. Thus, continuous variables in this study were described by median (interquartile range). Categorical variables were described by frequency and percentage. We used the Mann-Whitney $U$-test to compare differences between two independent groups, and the Kruskal-Wallis $H$-test for the multiple independent samples and inter-group comparisons. Spearman correlation was used to analyze the association between psychological health and coping style and disease awareness. Statistical significance was set at $\mathrm{p}<0.05$.

\section{Results}

\section{Demographic Characteristics and Information About COVID-19 Infection}

The sample comprised 409 (71.63\%) women and 162 (28.37\%) men. The respondents' age ranged from 18 to 60 years; $355(62.17 \%)$ were $18-30$ years old and the rest $(n=$ $216,37.83 \%)$ were over 30 years old. Two-hundred sixteen $(37.83 \%)$ respondents were from rural areas, while 74 $(12.96 \%)$ were from towns, and $281(49.21 \%)$ were from 


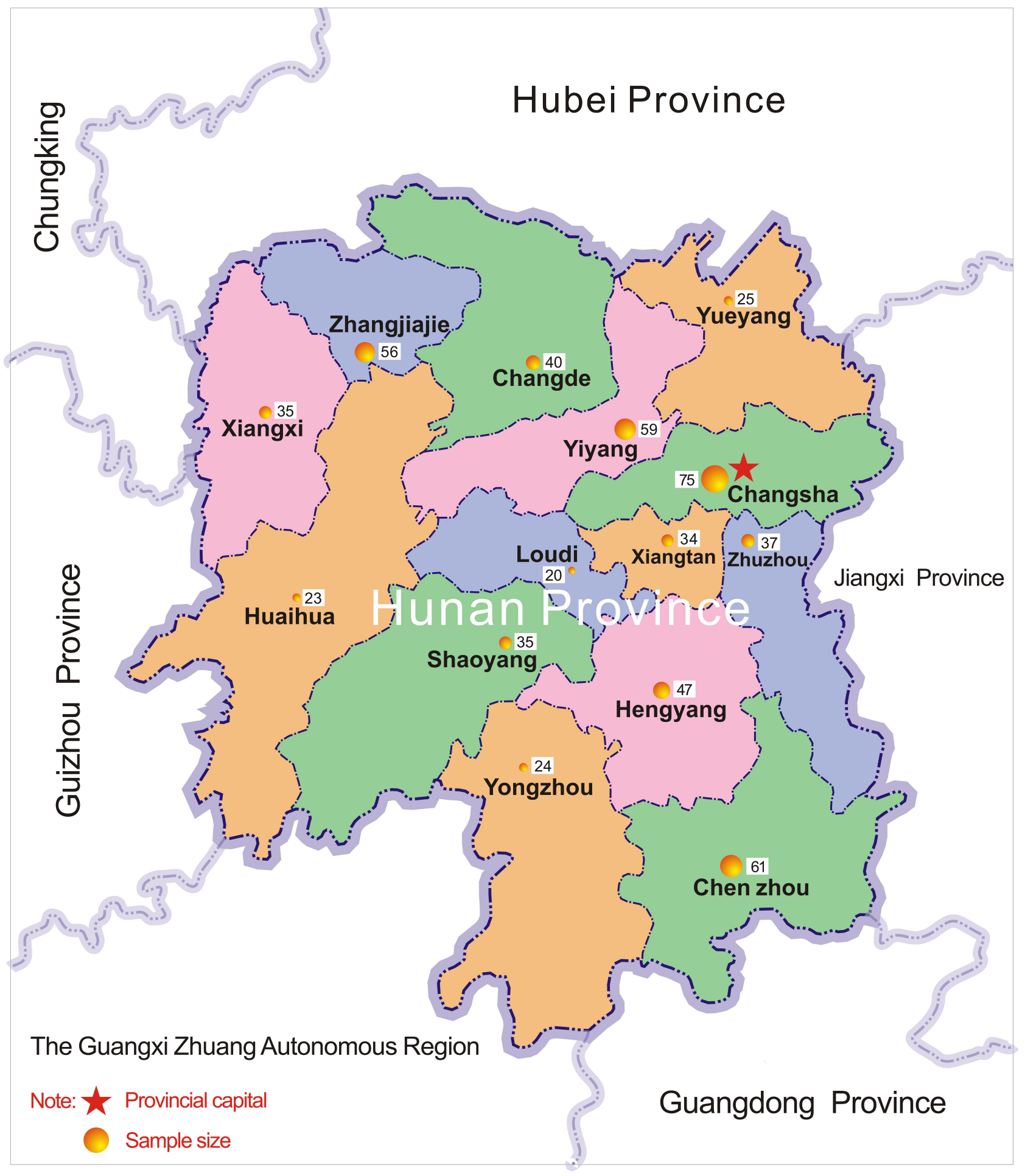

Figure 2 Distribution of the research samples across various cities of Hunan Province.

cities. The majority of participants $(\mathrm{n}=534,93.52 \%)$ were ethnically Han, while only $6.48 \%(n=37)$ were members of ethnic minorities. Over half $(n=329,57.62 \%)$ of the participants were unmarried, followed by married $(\mathrm{n}=230$, $40.28 \%)$ and divorced $(\mathrm{n}=12,2.10 \%)$ participants.
Regarding their education level, almost two-thirds ( $\mathrm{n}=379$, $66.37 \%$ ) of the participants had a bachelor's degree or above, $100(17.51 \%)$ participants had a junior college degree, and only $92(16.11 \%)$ had a senior high school degree or below. Additionally, $35.20 \%(\mathrm{n}=201)$ of participants were students, 
$28.20 \%(\mathrm{n}=161)$ were non-frontline medical staff, and $36.60 \%(n=209)$ were from other occupations (such as company employees, migrant workers, or merchants). More than one-third $(\mathrm{n}=201,35.20 \%)$ of participants had a monthly income of more than $5000 \mathrm{RMB}$, and over twofifths $(\mathrm{n}=249,43.61 \%)$ had a monthly income of less than or equal to 5000 RMB, while 121 (21.19\%) had no income. Most participants $(\mathrm{n}=518,90.72 \%)$ had no religious beliefs, while $53(9.28 \%)$ held one or more religious beliefs. During the Chinese New Year, most participants gathered with 3-5 family members $(n=262,45.88 \%)$, while a similar amount gathered with more than 5 family members $(n=266$,
$46.58 \%)$, and only a few $(\mathrm{n}=43,7.53 \%)$ gathered with $1-2$ family members (Table 1).

Regarding issues related to the COVID-19 pandemic, only a minority of participants had suffered COVID-19like symptoms (such as fever, fatigue, or cough; $n=13$, $2.28 \%)$, had eaten uncooked seafood or meat products $(\mathrm{n}=$ 29, 5.08\%), had had contact with people from Hubei Province/Wuhan in the past two weeks $(n=43,7.53 \%)$, or were unfamiliar with COVID-19 ( $\mathrm{n}=38,6.65 \%)$. However, most of the respondents had actively obtained knowledge on how to protect themselves from COVID-19 $(\mathrm{n}=539,94.40 \%)$, were able to discern the authenticity of

Table I Demographic Characteristics and Differences in Public Emergency Psychological State $(n=57 \mathrm{I})$

\begin{tabular}{|c|c|c|c|c|c|}
\hline \multicolumn{2}{|l|}{ Variables } & \multirow{2}{*}{$\begin{array}{l}\text { n (\%) } \\
334(58.49) \\
237(4 I .51)\end{array}$} & \multirow{2}{*}{$\begin{array}{l}\text { Mean } \\
\text { Rank }\end{array}$} & \multirow{2}{*}{$\begin{array}{l}\begin{array}{l}\text { Z-value or } \\
\text { H-value }\end{array} \\
-1.056\end{array}$} & \multirow{2}{*}{$\begin{array}{l}\text { p value } \\
0.291\end{array}$} \\
\hline Age (years) & $\begin{array}{l}18-29 \\
>30\end{array}$ & & & & \\
\hline Gender & $\begin{array}{l}\text { Male } \\
\text { Female }\end{array}$ & $\begin{array}{l}162(28.37) \\
409(71.63)\end{array}$ & $\begin{array}{l}291.19 \\
283.94\end{array}$ & -0.473 & 0.636 \\
\hline Place of residence & $\begin{array}{l}\text { Rural area } \\
\text { Town } \\
\text { City }\end{array}$ & $\begin{array}{l}216(37.83) \\
74(12.96) \\
28 I(49.2 I)\end{array}$ & $\begin{array}{l}290.5 I \\
303.30 \\
278.50\end{array}$ & 1.379 & 0.502 \\
\hline Ethnicity & $\begin{array}{l}\text { Han Chinese } \\
\text { Ethnic minority }\end{array}$ & $\begin{array}{l}534(93.52) \\
37(6.48)\end{array}$ & $\begin{array}{l}286.33 \\
281.19\end{array}$ & -0.183 & 0.854 \\
\hline Marital status & $\begin{array}{l}\text { Unmarried } \\
\text { Married } \\
\text { Divorced or widowed }\end{array}$ & $\begin{array}{l}329(57.62) \\
230(40.28) \\
12(2.10)\end{array}$ & $\begin{array}{l}282.40 \\
287.58 \\
354.38\end{array}$ & 2.240 & 0.326 \\
\hline Educational level & $\begin{array}{l}\text { Senior high school or below } \\
\text { Junior college } \\
\text { Undergraduate or above }\end{array}$ & $\begin{array}{l}92(16.11) \\
100(17.51) \\
379(66.37)\end{array}$ & $\begin{array}{l}301.57 \\
296.12 \\
279.55\end{array}$ & 1.775 & $0.4 I 2$ \\
\hline Occupation & $\begin{array}{l}\text { Student } \\
\text { Medical staff } \\
\text { Others (company employee, migrant } \\
\text { worker, or merchant) }\end{array}$ & $\begin{array}{l}201(35.20) \\
161(28.20) \\
209(36.60)\end{array}$ & $\begin{array}{l}274.72 \\
263.40 \\
314.26\end{array}$ & 10.100 & 0.006 \\
\hline Monthly income & $\begin{array}{l}\text { No income } \\
\leq 5000 \text { RMB } \\
>5000 \text { RMB }\end{array}$ & $\begin{array}{l}|2|(2 I .19) \\
249(43.6 I) \\
20 I(35.20)\end{array}$ & $\begin{array}{l}274.22 \\
285.65 \\
293.52\end{array}$ & 1.036 & 0.596 \\
\hline Religious beliefs & $\begin{array}{l}\text { No } \\
\text { Yes }\end{array}$ & $\begin{array}{l}518(90.72) \\
53(9.28)\end{array}$ & $\begin{array}{l}286.23 \\
283.76\end{array}$ & -0.104 & 0.917 \\
\hline $\begin{array}{l}\text { Number of family members present during } \\
\text { Chinese New Year }\end{array}$ & $\begin{array}{l}1-2 \\
3-5 \\
>5\end{array}$ & $\begin{array}{l}43(7.53) \\
262(45.88) \\
266(46.58)\end{array}$ & $\begin{array}{l}289.97 \\
274.15 \\
297.03\end{array}$ & 2.568 & 0.277 \\
\hline Family member who works as medical staff & $\begin{array}{l}\text { No } \\
\text { Yes }\end{array}$ & $\begin{array}{l}338(59.19) \\
233(40.81)\end{array}$ & $\begin{array}{l}290.32 \\
279.74\end{array}$ & -0.753 & 0.451 \\
\hline
\end{tabular}


COVID-19-related information ( $\mathrm{n}=456,79.86 \%$ ), were concerned about the COVID-19 pandemic $(\mathrm{n}=522$, $91.42 \%$ ), or knew the daily number of confirmed COVID-19 cases in China $(\mathrm{n}=506,88.62 \%)$. The number of the participants who spent less than 1 hour, 1-2 hours, and more than 2 hours on the COVID-19 pandemic information every day was 217 (38\%), 252 (44.13\%), and 102 (17.86\%), respectively. Most participants thought that the disclosure of information surrounding the COVID-19 pandemic was timely $(\mathrm{n}=378,66.20 \%)$ or fair $(\mathrm{n}=135$, $23.64 \%)$, while only $10.16 \%(\mathrm{n}=58)$ thought that the information disclosure was delayed. About $97.37 \%$ ( $n=$ 556) of participants acquired COVID-19-related information from the internet (via WeChat, Sina Weibo, TikTok, or from websites), followed by television broadcasts $(\mathrm{n}=$ 281, 49.21\%) and word-of-mouth from family, friends, and neighbors $(\mathrm{n}=186,32.57 \%)$. Newspapers and magazines were the least frequently used information source (n $=74,12.96 \%$ ). Table 2 presents participants' information about COVID-19 infection.

\section{Public Emergency Psychological State Questionnaire Scores}

The total mean score for the public emergency psychological state was $0.27(0.31)$, and the vast majority $(94.22 \%$, $\mathrm{n}=538)$ of participants reported a psychological score $<1$, while only $5.78 \%(n=33)$ of them had a score $\geq 1$. The score for fear was the highest at $0.89(0.83)$, followed by depression (0.11 [0.42]), and compulsion-anxiety (0.08 [0.25]). Neurasthenia and hypochondria exhibited the lowest scores at $<0.001(0.40)$ and $<0.001(0.02)$, respectively. Moreover, the prevalence of fear was the highest $(n=274$, $47.99 \%)$, followed by neurasthenia $(\mathrm{n}=59,10.33 \%)$, depression $(\mathrm{n}=52,9.11 \%)$, while hypochondriasis $(\mathrm{n}=$ $18,3.15 \%)$ and obsessive-compulsive anxiety $(\mathrm{n}=18$, $3.15 \%$ ) had the lowest prevalence (See Table 3).

\section{Differences in Public Emergency Psychological State}

The results of two independent samples from the MannWhitney $U$-test and the multiple independent samples from the Kruskal-Wallis $H$-test revealed significant differences among the following variables: occupation, symptoms of fever or fatigue, discernment of the authenticity of COVID-19 information, and level of concern regarding COVID-19 $(\mathrm{p}<0.05)$ (Tables 1 and 2$)$.

\section{Relationships Between Public Emergency Psychological State, Coping Style, and Disease Awareness}

In this study, the total mean scores for active coping style and avoidant coping style were 1.75 (1.08) and 0.75 (0.87), respectively. Disease awareness was at $3.81 \pm$ 0.83 points, with a score rate (the actual score/the maximum score $\times 100 \%$ ) of $76.2 \%$. Avoidant coping style was weakly positively correlated with the public emergency psychological state score $\left(r_{s}=0.257, p<0.01\right)$, depression $\left(r_{s}=0.141, p<0.01\right)$, neurasthenia $\left(r_{s}=0.204, p<0.01\right)$, fear $\left(r_{s}=0.186, p<0.01\right)$, compulsion-anxiety $\left(r_{s}=0.241\right.$, $\mathrm{p}<0.01)$, and hypochondria $\left(\mathrm{r}_{\mathrm{s}}=0.166, \mathrm{p}<0.01\right)$. Moreover, disease awareness was weakly negatively correlated with the public emergency psychological state $\left(r_{\mathrm{s}}=\right.$ $-0.124, p<0.01)$, depression $\left(r_{s}=-0.168, p<0.01\right)$, neurasthenia $\left(r_{\mathrm{s}}=-0.098, \mathrm{p}<0.05\right)$, and compulsionanxiety $\left(\mathrm{r}_{\mathrm{s}}=-0.184, \mathrm{p}<0.01\right)$, as shown in Table 4 .

\section{Discussion}

At the critical stage of curbing the spread of the virus, assessing the public's disease awareness, coping style, and psychological state is very important for helping develop adequate preventive psychological strategies. This study showed that the population of Hunan Province has adequate awareness of the COVID-19 pandemic and only a minority of them experience psychological distress during this period.

Our study found that the internet, especially social media, is currently the most used information source (97.37\%), which is consistent with the results of Yue et $\mathrm{al}^{36}$ and Chen et $\mathrm{al}^{37}$. This shows that the internet is a practical tool to promote public health. In the first quarter of 2020, Chinese spent $30 \%$ more time on internet apps, compared with $2019,{ }^{38}$ which suggests that people are more dependent on digital media than ever before due to the social isolation measures enacted by the government. Although the internet has been an important source of information during the COVID-19 pandemic, ${ }^{39}$ it has also been an important source of misinformation. ${ }^{40}$ Therefore, we argue that there is a need for a network gatekeeping mechanism to guarantee the provision of reliable scientific information during health crises such as this.

Our survey revealed that, from a psychological standpoint, the general public was only slightly affected by the COVID-19 outbreak, with the participants of our study exhibiting a total mean score of 0.27 (0.31). Further, only $5.78 \%$ of participants developed psychological 
Table 2 Participants' Information About COVID-I9 Infection and Differences in Public Emergency Psychological State $(\mathrm{n}=57 \mathrm{I})$

\begin{tabular}{|c|c|c|c|c|c|}
\hline \multicolumn{2}{|l|}{ Variables } & \multirow{2}{*}{$\begin{array}{l}\text { n (\%) } \\
558(97.72) \\
13(2.28)\end{array}$} & \multirow{2}{*}{$\begin{array}{l}\text { Mean } \\
\text { Rank }\end{array}$} & \multirow{2}{*}{$\begin{array}{l}\begin{array}{l}\text { Z-value or } \\
\text { H-value }\end{array} \\
-2.273\end{array}$} & \multirow{2}{*}{\begin{tabular}{|l} 
p value \\
0.023
\end{tabular}} \\
\hline Symptoms of fever or fatigue & $\begin{array}{l}\text { Absent } \\
\text { Present }\end{array}$ & & & & \\
\hline Ate uncooked seafood or meat products & $\begin{array}{l}\text { No } \\
\text { Yes }\end{array}$ & $\begin{array}{l}542(94.92) \\
29(5.08)\end{array}$ & $\begin{array}{l}283.40 \\
324.60\end{array}$ & -1.313 & 0.189 \\
\hline Had contact with people from Hubei Province/Wuhan & $\begin{array}{l}\text { No } \\
\text { Yes }\end{array}$ & $\begin{array}{l}528(92.47) \\
43(7.53)\end{array}$ & $\begin{array}{l}283.38 \\
318.21\end{array}$ & -1.332 & 0.183 \\
\hline Actively obtaining knowledge on protecting oneself from COVID-19 & $\begin{array}{l}\text { No } \\
\text { Yes }\end{array}$ & $\begin{array}{l}32(5.60) \\
539(94.40)\end{array}$ & $\begin{array}{l}293.50 \\
285.55\end{array}$ & -0.265 & 0.791 \\
\hline $\begin{array}{l}\text { Ability to discern the authenticity of COVID-19-related } \\
\text { information }\end{array}$ & $\begin{array}{l}\text { Unable } \\
\text { Able }\end{array}$ & $\begin{array}{l}115(20.14) \\
456(79.86)\end{array}$ & $\begin{array}{l}332.33 \\
274.31\end{array}$ & -3.371 & 0.001 \\
\hline Level of familiarity with COVID-19 & $\begin{array}{l}\text { Unfamiliar } \\
\text { Fair } \\
\text { Familiar }\end{array}$ & $\begin{array}{l}38(6.65) \\
215(37.65) \\
318(55.69)\end{array}$ & $\begin{array}{l}322.19 \\
295.79 \\
275.06\end{array}$ & 3.980 & 0.137 \\
\hline Level of concern regarding COVID-19 & $\begin{array}{l}\text { Unconcerned } \\
\text { Concerned }\end{array}$ & $\begin{array}{l}49(8.58) \\
522(91.42)\end{array}$ & $\begin{array}{l}334.81 \\
281.42\end{array}$ & -2.166 & 0.030 \\
\hline $\begin{array}{l}\text { Time spent on trying to acquire COVID-19-related knowledge } \\
\text { (hours) }\end{array}$ & $\begin{array}{l}<1 \\
1-2 \\
>2\end{array}$ & $\begin{array}{l}217(38.00) \\
252(44.13) \\
102(17.86)\end{array}$ & $\begin{array}{l}277.85 \\
285.69 \\
304.12\end{array}$ & 1.762 & 0.414 \\
\hline Awareness of daily number of confirmed COVID-19 cases in China & $\begin{array}{l}\text { Yes } \\
\text { No }\end{array}$ & $\begin{array}{l}65(11.38) \\
506(88.62)\end{array}$ & $\begin{array}{l}303.12 \\
283.80\end{array}$ & -0.889 & 0.374 \\
\hline Perception of timeliness announcements related to the pandemic & $\begin{array}{l}\text { Lagging } \\
\text { Fair } \\
\text { Timely }\end{array}$ & $\begin{array}{l}58(10.16) \\
135(23.64) \\
378(66.20)\end{array}$ & $\begin{array}{l}315.37 \\
296.51 \\
277.74\end{array}$ & 3.336 & 0.189 \\
\hline
\end{tabular}

Abbreviation: COVID-19, coronavirus disease 2019.

Table 3 Public Emergency Psychological State Questionnaire Scores $(n=57 \mathrm{I})$

\begin{tabular}{|l|l|l|l|l|}
\hline Variables & Score Ranges (Points) & Median (Interquartile Range) & $\geq$ I Point (n, \%) & $<$ I Point (n, \%) \\
\hline Fear & $0-3$ & $0.89(0.83)$ & $274(47.99 \%)$ & $297(52.01 \%)$ \\
Neurasthenia & $0-3$ & $<0.001(0.40)$ & $59(10.33 \%)$ & $512(89.67 \%)$ \\
Depression & $0-2.5$ & $0.11(0.42)$ & $52(9.11 \%)$ & $519(90.89 \%)$ \\
Obsessive-compulsive anxiety & $0-2.0$ & $0.08(0.25)$ & $18(3.15 \%)$ & $553(96.85 \%)$ \\
Hypochondriasis & $0-2.0$ & $<0.001(0.02)$ & $18(3.15 \%)$ & $553(96.85 \%)$ \\
Public Emergency Psychological State & $0-2.1$ & $0.27(0.31)$ & $33(5.78 \%)$ & $538(94.22 \%)$ \\
\hline
\end{tabular}

Table 4 Correlations Between Public Emergency Psychological State, Coping Style, and Disease Awareness $\left(R_{s}, n=57 \mathrm{I}\right)$

\begin{tabular}{|l|l|l|l|l|l|l|}
\hline Variable & Depression & Neurasthenia & Fear & Compulsion-Anxiety & Hypochondria & Total Mean Score \\
\hline Active coping style & -0.055 & -0.017 & 0.069 & -0.055 & 0.002 & 0.027 \\
Avoidant coping style & $0.141^{* *}$ & $0.204^{* *}$ & $0.186^{* *}$ & $0.241^{* *}$ & $0.166^{* *}$ & $0.257^{* *}$ \\
Disease awareness & $-0.168^{* *}$ & $-0.098^{*}$ & -0.053 & $-0.184^{* *}$ & -0.061 & $-0.124^{* *}$ \\
\hline
\end{tabular}

Notes: ${ }^{*} \mathrm{p}<0.05,{ }^{*} \mathrm{p}<0.01$. 
distress, which is far lower than the Chinese national average $(53.8 \%),{ }^{8}$ as well as the average of other countries. $9,10,41,42$ This may be owed to various reasons. First, unlike other studies, we used a scale specifically targeted for public health emergencies, which may have been the primary reason for the low prevalence of psychological distress. Second, COVID-19 confirmed cases reported in Hunan Province maintained a small daily increase (less than 100 cases) ${ }^{43}$ during the research period, which may mean that the pandemic did not cause great public stress. Third, strong social support is related to a reduced likelihood to develop psychological distress. ${ }^{44}$ Most of the participants $(92.47 \%)$ in this study gathered with more than two family members and could get more support and care from their families during social isolation. Fourth, the timely response of the Chinese authorities, effective preventive measures, and the transparency of the media increased the social health resources of the public. However, as in other studies during the COVID19 pandemic, ${ }^{45,46}$ and during the SARS-CoV period, ${ }^{32,47}$ participants reported a higher prevalence of fear in our study. Further, previous studies have reported that more than $80 \%$ of the public were worried about contracting the virus. ${ }^{48,49}$ Worry and fear are understandable emotional responses within stressful and uncertain contexts, such as in the ongoing health crisis. In addition, as other studies have reported, ${ }^{10,42}$ some public may have suffered from psychological disorders like neurasthenia, depression, hypochondriasis, and obsessive-compulsive anxiety. Thus, more attention should be paid to these perceived negative emotions and multifaceted interventions may be considered to support the mental health of these people.

We identified that the avoidant coping style was associated with poor mental health, which is consistent with the results of Dawson et $\mathrm{al}^{50}$ and Gurvich et $\mathrm{al}^{51}$, who suggest that avoidance coping behaviors (such as fantasy, avoidance, self-blame, and laissez-faire) negatively affect psychological well-being. Previous studies on psychological crises or emergency events reported that avoidant coping is correlated with lower psychological endurance, ${ }^{52}$ less perceived control, ${ }^{53}$ and higher levels of anxiety-like behavior. ${ }^{54}$ However, unlike those of previous studies, ${ }^{53,55}$ our findings showed that there was little correlation between an active coping style and participants' public emergency psychological state. It is unclear whether this is due to variations in research populations and measurement tools or due to social isolation during the pandemic. Additionally, COVID-19-related challenges may prevent individuals from successfully relieving their stress through work, study or other activities. This is supported by Wang et al, who reported that the avoidant coping style had greater impact on individuals' psychological distress, compared with the active coping style, during the lockdown period. ${ }^{56}$ This could suggest that psychological interventions like cognitive therapy are required to change maladaptive behaviors and to control avoidance coping styles.

People's adherence to COVID-19 prevention measures is greatly affected by their relevant knowledge and attitudes. $^{57}$ In our study, more than $90 \%$ of participants mentioned that they were concerned about the pandemic, and actively acquired COVID-19-related knowledge. Similar to the findings in other countries, ${ }^{58,59}$ participants showed positive attitudes toward protective measures and were willing to engage in preventive actions against the pandemic. The present study also showed that the general public's disease awareness during the COVID-19 pandemic was moderately high $(3.81 \pm 0.83)$, compared with the public's awareness during the outbreak of the severe acute respiratory syndrome (SARS) (mean score: 3.15 ) in $2003 .^{29}$ The 2003 SARS outbreak has taught valuable lessons to the Chinese people. ${ }^{60}$ The massive awareness campaigns such as implementing public health policies, providing public health education, and disseminating information to the public, ${ }^{61}$ might improve public knowledge regarding COVID-19. Disease awareness in our study $(76.2 \%)$ was lower than that reported by a contemporaneous study in Hubei Province, China $(90 \%)^{62}$ and another one from Vietnam $(92.2 \%) .{ }^{28}$ This difference may be due to the gap between self-assessed and tested knowledge level. Participants in our study might have felt uncertain regarding their disease awareness during the pandemic, which could have lowered the self-evaluation of their knowledge level.

Participants' disease awareness was negatively correlated with the public emergency psychological state, which is supported by previous studies. 8,63 Documented studies have shown that knowledge is related to more preventive behaviors $^{28,64}$ and the involvement in these behaviors and various strategies can facilitate the maintenance of psychological well-being. Additionally, insufficient disease awareness can lead to the perpetuation of misinformation and superstitious beliefs, which not only affect the correct implementation of preventive measures, but also aggravate public panic. ${ }^{65}$ With the global spread of COVID-19, awareness has increased among the general public and knowledge regarding the 
COVID-19 pandemic has reached a relatively high level. ${ }^{66}$ However, there is still room for effort in driving COVID-19 related knowledge to preventive behavior changes.

In terms of demographics, company employees, migrant workers, and businessmen were more susceptible to psychological disorders during the COVID-19 pandemic. However, studies on the differences in mental health between different occupations have not provided conclusive results. For example, Rehman et $\mathrm{al}^{67}$ found that students and healthcare workers were at higher risk of developing anxiety and depression. By contrast, a national survey in China showed that migrant workers experienced the highest psychological distress, compared with other professions. ${ }^{7}$ In our study participants were predominantly college students $(35.20 \%)$ with a high education level, followed by non-frontline medical staff $(28.20 \%)$ with extensive medical knowledge, and other professionals $(36.60 \%)$, including company employees, migrant workers, and businessmen, who were greatly affected by the lockdown and unemployment, which yielded a slightly different trend in occupation, compared with other studies.

In this study, we noted that participants who reported having recently had symptoms of fever or fatigue had a greater likelihood of experiencing psychological problems (such as fear, depression, and neurasthenia), which is congruent with the findings of Wang et al ${ }^{8}$ and $\mathrm{Fu}$ et $\mathrm{al}^{68}$. According to the 2019-nCoV Pneumonia Control Protocol, ${ }^{69}$ people with COVID-19-like symptoms (such as fever, fatigue, and dry cough) are required to self-isolate or receive COVID-19 testing, diagnosis, and treatment in designated medical institutions. Recently, $\mathrm{Yu}$ et $\mathrm{al}^{55}$ reported that individuals suspected of having COVID-19 tend to adopt negative coping styles, receive less social support, and have low utilization rates of social support. Continuous forced isolation and uncertainty about their health status may lead to patients' sensitivity, suspicion, fear, and cognitive deviation (such as emotional processing disorders ${ }^{70}$ that could aggravate mental health problems). Individuals' discernment of acquired information is important for their understanding of the correct protective measures against the epidemic. Our results revealed that this ability is correlated with individuals' psychological state. Individuals with limited discernment ability cannot effectively analyze and process a large volume of information, which may cause information overload and information anxiety, ${ }^{71}$ and may also lead to poor healthrelated decision-making. ${ }^{72}$

Our study showed that individuals who were unconcerned about the COVID-19 pandemic were more vulnerable to the negative psychological outcomes. Evidence has shown that unconcerned attitudes often lead to a lack of COVID-19 awareness, ${ }^{73}$ low compliance with the recommended preventive behaviors, ${ }^{74}$ marginalization from accessing public health information, and a higher susceptibility to rumors and panic. ${ }^{75}$ Therefore, in addition to releasing evidence-based information to help the public prioritize scientific methods and discard superstitious opinions, it is also necessary to guide individuals with COVID-19-like symptoms, limited discernment competence, and unconcerned attitudes to engage in preventive measures. Attention and assistance to these vulnerable groups should be a global priority.

\section{Limitations}

This study has several limitations. First, this online survey recruited participants through social media apps and excluded people without internet access. Second, the participants in this study were unevenly distributed in age and occupation, more than half of the participants were aged between 18 and 30 years, and most were medical students and non-front-line medical staff, which limits the generalization of our results. Third, in order to maintain an appropriate questionnaire-filling time and to optimize the validity of the questionnaire, social support and personality traits were not registered. Fourth, the self-report questionnaire with closed questions hampered an in-depth exploration of the participants' subjective thoughts and it remains unclear whether the data were influenced by social expectations. Future studies should recruit participants from various occupations and age groups, be based on field surveys, and include other variables in the stress system model.

\section{Conclusions}

Although participants experienced inevitable psychological distress during the COVID-19 pandemic, with fear being the most common, most were in a positive psychological state. We observed that the higher the participants' avoidant coping style scores, the more severe their public emergency psychological state, and that the higher the participants' level of disease awareness, the milder their stress response. In Hunan Province, the COVID-19 pandemic appears to have a greater psychological impact on employees (such as 
company employees, migrant workers, and businessmen), individuals with COVID-19-like symptoms, as well as on individuals with limited discernment competence and unconcerned attitudes. With the continuous spread of the COVID-19 epidemic, efforts to develop actionable policies and massive healthcare education campaigns are necessary. Multi-departmental, multi-resource, and multi-component psychological guidelines and interventions still need further development, especially for vulnerable individuals at greater risk of psychological distress.

\section{Ethical Approval}

The medical ethics committee of Xiangnan University approved this study (reg. no. KY- 202002001).

\section{Acknowledgments}

First, we would like to thank Xiangnan University for approving and supporting this study. Second, we would like to thank the Questionnaire Star for providing us with the opportunity to conduct the online survey. Third, we would like to thank Editage (www.editage.com) for their linguistic assistance during the revision of this manuscript. Finally, we would like to express our gratitude to all the participants for contributing valuable data.

\section{Funding}

This study was supported by the Hunan Health Commission Fund (grant no. 20201138, 20200764) and the Hunan Social Science Achievement Evaluation Committee (grant no. XSP20YBC164).

\section{Disclosure}

The authors have no conflicts of interest to report.

\section{References}

1. World Health Organization. Coronavirus disease 2019 (COVID-19) situation report - 46; 2020. Available at: https://apps.who.int/iris/bit stream/handle/10665/331443/nCoVsitrep06Mar2020-eng.pdf. Accessed March 12, 2020.

2. Global Times. 25 provinces, cities, and autonomous regions activated major public health emergency primary responses [EB/OL]; 2020. Available from: https://3w.huanqiu.com/a/c36dc8/9CaKrnKp4bG? agt=8.wap,02-05. Accessed June 26, 2020.

3. Chen S, Yang J, Yang W, Wang C, Bärnighausen T. COVID-19 control in China during mass population movements at New Year. Lancet. 2020;395(10226):764-766. doi:10.1016/S0140-6736(20)30421-9

4. World Health Organization. Mental health and psychosocial considerations during COVID-19 outbreak [EB/OL]; 2020. Available from: https:// www.who.int/publications/i/item/mental-health-and-psychosocialconsiderations-during-the-covid-19-outbreak. Accessed June 26, 2020.

5. Pfefferbaum B, North CS. Mental health and the Covid-19 pandemic. N Engl J Med. 2020;383(6):510-512. doi:10.1056/NEJMp2008017
6. Liu Q, Luo D, Haase JE, et al. The experiences of health-care providers during the COVID-19 crisis in China: a qualitative study. Lancet Glob Health. 2020;8(6):e790-e798. doi:10.1016/S2214-109X (20)30204-7

7. Qiu J, Shen B, Zhao M, Wang Z, Xie B, Xu Y. A nationwide survey of psychological distress among Chinese people in the COVID-19 epidemic: implications and policy recommendations. Gen Psychiatr. 2020;33(2):e100213. doi:10.1136/gpsych-2020-100213

8. Wang C, Pan R, Wan X, et al. Immediate psychological responses and associated factors during the initial stage of the 2019 coronavirus disease (COVID-19) epidemic among the general population in China. Int J Environ Res Public Health. 2020;17(5):1729. doi:10. 3390/ijerph17051729

9. Pierce M, Hope H, Ford T, et al. Mental health before and during the COVID-19 pandemic: a longitudinal probability sample survey of the UK population. Lancet Psychiatr. 2020;7(10):883-892. doi:10.1016/ S2215-0366(20)30308-4

10. Rodríguez-Rey R, Garrido-Hernansaiz H, Collado S. Psychological impact and associated factors during the initial stage of the coronavirus (COVID-19) pandemic among the general population in Spain. Front Psychol. 2020;11:1540. doi:10.3389/fpsyg.2020.01540

11. Fisher JR, Tran TD, Hammarberg K, et al. Mental health of people in Australia in the first month of COVID-19 restrictions: a national survey. Med J Aust. 2020;213(10):458-464. doi:10.5694/mja2.50831

12. Casagrande M, Favieri F, Tambelli R, Forte G. The enemy who sealed the world: effects quarantine due to the COVID-19 on sleep quality, anxiety, and psychological distress in the Italian population. Sleep Med. 2020;75:12-20. doi:10.1016/j.sleep.2020.05.011

13. Forte G, Favieri F, Tambelli R, Casagrande M. COVID-19 pandemic in the Italian population: validation of a post-traumatic stress disorder questionnaire and prevalence of PTSD symptomatology. Int J Environ Res Public Health. 2020;17(11):4151. doi:10.3390/ijerph17114151

14. Forte G, Favieri F, Tambelli R, Casagrande M. The enemy which sealed the world: effects of COVID-19 diffusion on the psychological state of the Italian population. J Clin Med. 2020;9(6):1802. doi: $10.3390 / \mathrm{jcm} 9061802$

15. Lazarus RS, Folkman S. Stress, Appraisal, and Coping. New York: Springer; 1984.

16. Yang L, Zhao Y, Wang Y, et al. The effects of psychological stress on depression. Curr Neuropharmacol. 2015;13(4):494-504. doi:10.21 74/1570159X1304150831150507

17. Arslan G, Yıldırım M, Tanhan A, Buluş M, Allen KA. Coronavirus stress, optimism-pessimism, psychological inflexibility, and psychological health: psychometric properties of the Coronavirus Stress Measure. Int J Ment Health Addict. 2020;4:1-17. doi:10.1007/s114 69-020-00337-6

18. Yaribeygi H, Panahi Y, Sahraei H, Johnston TP, Sahebkar A. The impact of stress on body function: a review. EXCLI J. 2017;16: 1057-1072.

19. Brosschot JF, Verkuil B, Thayer JF. The default response to uncertainty and the importance of perceived safety in anxiety and stress: an evolution-theoretical perspective. J Anxiety Disord. 2016;41:22-34. doi:10.1016/j.janxdis.2016.04.012

20. Coyne JC, Downey G. Social factors and psychopathology: stress, social support, and coping processes. Ann Rev Psychol. 1991;42 (1):401-425. doi:10.1146/annurev.ps.42.020191.002153

21. Matheny KB, Aycock DW, Pugh JL, Curlette WL, Silva Cannella K. Stress coping: a qualitative and quantitative synthesis with implications for treatment. Couns Psychol. 1986;14:499-549. doi:10.1177/ 0011000086144001

22. Yaacob SN, Fam JY, Hasbullah M, Arshat Z, Juhairi R. Negative life events and mental health problem: the importance of coping strategy. Pertanika J Soc Sci Hum. 2019;27(S1):77-87.

23. Hussain MM, Khalily MT, Ahmad I. Effects of internalizing problems on quality of life among cardiac patients: mediating role of coping strategies. J Pak Med Assoc. 2020;70(1):64-69. 
24. Zimmer-Gembeck MJ, Skinner EA. The development of coping: implications for psychopathology and resilience. In: Cicchetti D, editor. Developmental Psychopathology. 3rd. Vol. 4. New York: Wiley; 2016.

25. Casagrande M, Boncompagni I, Mingarelli A, et al. Coping styles in individuals with hypertension of varying severity. Stress Health. 2019;35(4):560-568. doi:10.1002/smi.2889

26. Wolf MS, Serper M, Opsasnick L, et al. Awareness, attitudes, and actions related to COVID-19 among adults with chronic conditions at the onset of the US outbreak: a cross-sectional survey. Ann Intern Med. 2020;173(2):100-109. doi:10.7326/M20-1239

27. Janz NK, Becker MH. The health belief model: a decade later. Health Educ Q. 1984;11(1):1-47. doi:10.1177/109019818401100101

28. Van Nhu H, Tuyet-Hanh TT, Van NTA, Linh TNQ, Tien TQ. Knowledge, attitudes, and practices of the Vietnamese as key factors in controlling COVID-19. J Community Health. 2020;45(6):12 63-1269.

29. Chen C, He H, Yan J, He X, Chen S, Shi K. The impact of SARS on the mentality and behaviour of people. J Ningbo Inst Educ. 2003;5:1-5.

30. Okoro J, Odionye T, Nweze B, et al. COVID-19 pandemic, psychological response to quarantine, and knowledge of the disease among inmates in a Nigerian custodial center. Emerald Open Res. 2020;2 (26):26. doi:10.35241/emeraldopenres.13684.2

31. Kendall M. Multivariate Analysis. 2nd ed. London: Charles Griffin \& Co. LTD; 1980.

32. Gao Y, Xu M, Yang Y, Yao K. Discussion on the coping style of undergraduates and the correlative factors during the epidemic period of SARS. Chin Med Ethics. 2004;17:60-63.

33. Zhang Z. Manual of Behavioral Medicine Scale. Beijing: Chinese Medical Multimedia Press; 2005.

34. Yang Q, Zhang Y, Xu Y, Zheng J, Lin Z. Investigation on psychological stress in fighting against corona virus disease 2019 among community residents. Chin Nurs Res. 2020;34(7):1140-1145.

35. Xie Y. Preliminary study on the reliability and validity of the simple coping style scale. J Clin Psychol. 1998;23:53-54.

36. Yue S, Zhang J, Cao M, Chen B. Knowledge, attitudes and practices of COVID-19 among urban and rural residents in China: a cross-sectional study. J Community Health. 2020. doi:10.1007/ s10900-020-00877-x

37. Chen Y, Jin YL, Zhu LJ, et al. The network investigation on knowledge, attitude and practice about Novel coronavirus pneumonia of the residents in Anhui Province [Originally in Chinese]. Zhonghua $Y u$ Fang Yi Xue Za Zhi [Chinese Journal of Preventive Medicine]. 2020;54:E004.

38. Venkatraman A Weekly time spent in apps grows $20 \%$ year over year as people hunker down at home[EB/OL]. App Annie. Available from: https://www.appannie.com/en/insights/market-data/weekly-timespent-in-apps-grows-20-year-over-year-as-people-hunker-down-athome/. Accessed October 26, 2020.

39. Zhang D, Zhou L, Lim J. From networking to mitigation: the role of social media and analytics in combating the COVID-19 pandemic. Info Syst Manag. 2020;37(4):318-326. doi:10.1080/10580530.20 20.1820635

40. Apuke OD, Omar B. Fake news and COVID-19: modelling the predictors of fake news sharing among social media users [published online ahead of print]. Telemat Inform. 2020;101475. doi:10.1016/j. tele. 2020.101475

41. Cortés-Álvarez NY, Piñeiro-Lamas R, Vuelvas-Olmos CR. Psychological effects and associated factors of COVID-19 in a Mexican sample. Disaster Med Public Health Prep. 2020;14 (3):413-424. doi:10.1017/dmp.2020.215

42. Moccia L, Janiri D, Pepe M, et al. Affective temperament, attachment style, and the psychological impact of the COVID-19 outbreak: an early report on the Italian general population. Brain Behav Immun. 2020;87:75-79. doi:10.1016/j.bbi.2020.04.048
43. Hunan Health Committee. Updated information on the Novel Coronavirus Pneumonia cases in Hunan [EB/OL]. http://wjw.hunan. gov.cn/wjw/qwfb/202002/11169931/i mages/ 5f657cdfb66f447fbcf049b329085686.jpg. Accessed October 26, 2020.

44. Guilaran J, de Terte I, Kaniasty K, Stephens C. Psychological outcomes in disaster responders: a systematic review and meta-analysis on the effect of social support. Int J Disaster Risk Sci. 2018;9 (3):344-358. doi:10.1007/s13753-018-0184-7

45. Zhang Y, Ma ZF. Impact of the COVID-19 pandemic on mental health and quality of life among local residents in Liaoning Province, China: a cross-sectional study. Int J Environ Res Public Health. 2020;17(7):2381. doi:10.3390/ijerph17072381

46. Asmundson GJG, Taylor S. Coronaphobia: fear and the 2019-nCoV outbreak. J Anxiety Disord. 2020;70:102196. doi:10.1016/j.janxdis.20 20.102196

47. Ding S, Shi J, Wang T. Investigation on mental states of inhabitants during epidemic outbreak stage of SARS. Chin J Public Health. 2005;21(9):1119-1120.

48. Abdelhafiz AS, Mohammed Z, Ibrahim ME, et al. Knowledge, perceptions, and attitude of Egyptians towards the novel coronavirus disease (COVID-19). J Community Health. 2020;45(5):881-890. doi:10.1007/s10900-020-00827-7

49. Kwok KO, Li KK, Chan HHH, et al. Community responses during early phase of COVID-19 epidemic, Hong Kong. Emerg Infect Dis. 2020;26(7):1575-1579. doi:10.3201/eid2607.200500

50. Dawson DL, Golijani-Moghaddam N. COVID-19: psychological flexibility, coping, mental health, and wellbeing in the UK during the pandemic. J Contextual Behav Sci. 2020;17:126-134. doi:10. 1016/j.jcbs.2020.07.010

51. Gurvich C, Thomas N, Thomas EH, et al. Coping styles and mental health in response to societal changes during the COVID-19 pandemic. Int J Soc Psychiatry. 2020;002076402096179.

52. Wang L, Kang C, Yin Z, Su F. Psychological endurance, anxiety, and coping style among journalists engaged in emergency events: evidence from China. Iran J Public Health. 2019;48(1):95-102.

53. Dijkstra MT, Homan AC. Engaging in rather than disengaging from stress: effective coping and perceived control. Front Psychol. 2016;7:1415. doi:10.3389/fpsyg.2016.01415

54. Quah SKL, Cockcroft GJ, McIver L, Santangelo AM, Roberts AC. Avoidant coping style to high imminence threat is linked to higher anxiety-like behavior. Front Behav Neurosci. 2020;14:34. doi:10. 3389/fnbeh.2020.00034

55. Yu H, Li M, Li Z, et al. Coping style, social support and psychological distress in the general Chinese population in the early stages of the COVID-19 epidemic. BMC Psychiatr. 2020;20(1):426. doi:10.11 86/s12888-020-02826-3

56. Wang H, Xia Q, Xiong Z, et al. The psychological distress and coping styles in the early stages of the 2019 coronavirus disease (COVID-19) epidemic in the general mainland Chinese population: a web-based survey. PLoS One. 2020;15(5):e0233410. doi:10.1371/ journal.pone. 0233410

57. Dardas LA, Khalaf I, Nabolsi M, Nassar O, Halasa S. Developing an understanding of adolescents' knowledge, attitudes, and practices toward COVID-19. J Sch Nurs. 2020;36(6):430-441. doi:10.1177/ 1059840520957069

58. Alhazmi A, Ali MHM, Mohieldin A, Aziz F, Osman OB, Ahmed WA. Knowledge, attitudes and practices among people in Saudi Arabia regarding COVID-19: a cross-sectional study. J Public Health Res. 2020;9(3):1867. doi:10.4081/jphr.2020.1867

59. Sadiq A, Saleem MS, Malik M, Malik MI, Akhtar FK, Waheed KJB. How COVID-19 is changing behaviors of population: a study from Punjab. Biomedica. 2020;36:239-245.

60. Bouey J. Strengthening China's public health response system: from SARS to COVID-19. Am J Public Health. 2020;110(7):939-940. doi:10.2105/AJPH.2020.305654 
61. He AJ, Shi Y, Liu H. Practice, crisis governance, Chinese style: distinctive features of China's response to the Covid-19 pandemic. Policy Design Pract. 2020;3(3):242-258. doi:10.1080/25741292. 2020.1799911

62. Zhong BL, Luo W, Li HM, et al. Knowledge, attitudes, and practices towards COVID-19 among Chinese residents during the rapid rise period of the COVID-19 outbreak: a quick online cross-sectional survey. Int $J$ Biol Sci. 2020;16(10):1745. doi:10.7150/ijbs.45221

63. Du J, Dong L, Wang T, et al. Psychological symptoms among frontline healthcare workers during COVID-19 outbreak in Wuhan. Gen Hosp Psychiatry. 2020.

64. Tenkorang EY. Effect of knowledge and perceptions of risks on Ebola-preventive behaviours in Ghana. Int Health. 2018;10 (3):202-210. doi:10.1093/inthealth/ihy009

65. Taher M, Pashaeypoor S, Cheraghi MA, Karimy M, Hoseini ASS. Superstition in health beliefs: concept exploration and development. J Family Med Prim Care. 2020;9(3):1325-1330. doi:10.4103/jfmpc. jfmpc_871_19

66. Saadatjoo S, Miri M, Hassanipour S, Ameri H, Arab-Zozani M. A systematic review of the knowledge, attitudes, and practices of physicians, health workers, and the general population about Coronavirus disease 2019 (COVID-19). medRxiv. 2020. doi:10.11 01/2020.10.04.20206094v1

67. Rehman U, Shahnawaz MG, Khan NH, et al. Depression, anxiety and stress among Indians in times of COVID-19 lockdown. Community Ment Health J. 2020;1-7. doi:10.1007/s10597-020-00664-x.
68. Fu R, Zhang Y. Case report of a patient with suspected COVID-19 with depression and fever in an epidemic stress environment. Gen Psychiatr. 2020;33(3):e100218. doi:10.1136/gpsych-2020-100218

69. National Health Commission of People's Republic of China. Protocol on prevention and control of COVID-19 (Edition 6) [EB/OL]. Available from: http://en.nhc.gov.cn/2020-03/29/c_78467.htm. Accessed October 26, 2020.

70. Hampshire A, Trender W, Chamberlain S, et al. Cognitive deficits in people who have recovered from COVID-19 relative to controls: an $\mathrm{N}=84,285$ online study. medRxiv. 2020.

71. Laato S, Islam AKMN, Islam MN, Whelan EJEJOIS. What drives unverified information sharing and cyberchondria during the COVID-19 pandemic? Eur J Info. 2020;29(3):288-305. doi:10.10 80/0960085X.2020.1770632

72. Allcott H, Gentzkow M. Social media and fake news in the 2016 election J Econ Perspect. 2017;31(2):211-236. doi:10.1257/jep.31.2.211

73. Roy D, Tripathy S, Kar SK, Sharma N, Verma SK, Kaushal V. Study of knowledge, attitude, anxiety \& perceived mental healthcare need in Indian population during COVID-19 pandemic. Asian J Psychiatr. 2020;51:102083. doi:10.1016/j.ajp.2020.102083

74. Kamenidou IE, Stavrianea A, Liava C. Achieving a COVID-19 free country: citizens preventive measures and communication pathways. Int J Environ Res Public Health. 2020;17(13):4633. doi:10.3390/ ijerph17134633

75. Roozenbeek J, Schneider CR, Dryhurst S, et al. Susceptibility to misinformation about COVID-19 around the world. Royal Soc Open Sci. 2020;7(10):201199. doi:10.1098/rsos.201199
Risk Management and Healthcare Policy

\section{Publish your work in this journal}

Risk Management and Healthcare Policy is an international, peerreviewed, open access journal focusing on all aspects of public health, policy, and preventative measures to promote good health and improve morbidity and mortality in the population. The journa welcomes submitted papers covering original research, basic science, clinical \& epidemiological studies, reviews and evaluations, guidelines, expert opinion and commentary, case reports and extended reports. The manuscript management system is completely online and includes a very quick and fair peer-review system, which is all easy to use. Visit http://www.dovepress.com/testimonials.php to read real quotes from published authors. 